\title{
An Empirical Analysis of the Relationship Between China's Economic Growth and the Stock Market
}

\author{
Mingwei Zhou \\ School of Economics and Management \\ Nanjing University of Science and Technology \\ Nanjing, China
}

\author{
Yingchao Shang \\ School of Economics and Management \\ Nanjing University of Science and Technology \\ Nanjing, China
}

\begin{abstract}
This article mainly uses econometric methods such as cointegration tests, variance decomposition to make an empirical study the relationship on the growth of GDP and the stock market. The results show that there is a long-term equilibrium relationship between the growth of GDP and the stock market after the seasonally adjusted, and there is a Granger causality between GDP and the stock market turnover. The change of GDP will cause the change of the turnover of the stock market; the variance from GDP is greater than the stock market turnover. The GDP growth has a guiding role in the development and promotion of the stock futures market.
\end{abstract} GDP

Keywords-economic growth; stock market; relationship;

\section{INTRODUCTION}

The stock market is an important part of the financial market, which has an important impact on the development of the national economy. The stock market has the important function of connecting the production, manufacturing and service links and realizing the closure of the industrial chain. The stock market is developing in the macro - economic environment, and at the same time serving the development of the national economy. The cycle of the stock market is closely related to the operation of the economic cycle. The root of the volatility of the stock market lies in the cycle of the economy itself. The price of the stock market, as the leading indicator of the commodity price of the market economy, has played the role of the "barometer" of the market economy.

Since the emergence of the stock market, the relationship between the stock market and economic growth has been brought into the perspective of economists. It is a matter of recent decades to systematically study the relationship between stock market and economic growth with the tools of modern economics. Especially after 1990s, economists begin to develop and apply to the stock market from different angles (such as the efficiency of capital formation, information transfer, risk decentralization, etc.). The relationship between economic growth and the development of the stock market has been studied in a more deep and systematic way. This paper attempts to analyze the relationship between the stock market related indexes and the GDP growth level through the econometric model to reveal the internal relationship between the stock market and the macro-economy.

\section{RESEARCH METHODS}

First, the unit root test of the GDP growth rate and the stock market growth rate sequence is used to determine the stability of the two sets of sequences. On this basis, the vector autoregressive model is established. Then, based on the maximum lag order obtained by the VAR model, the cointegration test is used to test whether there is a cointegration relationship between the GDP growth rate sequence and the stock market growth rate sequence with the help of Johansen cointegration test, to further find out whether there is a long-term equilibrium relationship between the GDP growth rate sequence and the stock market growth rate sequence.

\section{A. Season Adjustment Selection}

Seasonal adjustment model is a time series model with seasonal variation law. Due to the seasonal fluctuation of GDP and stock market turnover, seasonal adjustment should be carried out when analyzing the dynamic relationship between the two.

\section{B. Johansen Cointegration Test}

The purpose of cointegration test is to determine whether a set of unstable sequences is cointegration. The VAR model with the order of $\mathrm{P}$ is considered.

$$
y_{t}=A_{t} y_{t-1}+\ldots \ldots+A_{p} y_{t-p}+B x_{t}+\varepsilon_{t}
$$

\section{Granger Causality Test}

The main cause of Granger causality test is whether there is a causal relationship between test variables

$$
y_{t}=\alpha_{0}+\sum_{i=1}^{k} \alpha_{i} y_{t-i}+\sum_{i=1}^{k} \beta_{i} x_{t-i}
$$

\section{Variance Analysis}

When examining the VAR model, the variance decomposition method can also be used to study the dynamic characteristics of the model. The main idea is to decompose the fluctuation of each endogenous variable in the system into $\mathrm{k}$ components associated with the new interest of the 
equations, so as to understand the relative importance of the information to the endogenous variables in the model.

If the share of the information in a market is relatively large, it shows that the market has absorbed more market information, that is, it plays a more important role in the price discovery function.

\section{E. Impulse Response Function}

To further characterize the interaction between stock market and GDP growth, we use the impulse response function analysis method to further study it. The main idea of the impulse response function is to analyze the effect of the impact of a standard error of the residual term in the error correction model on the stock market and GDP growth.

\section{SAMPLE DATA}

The study tries to reveal the relationship between China's stock market and the overall macro-economy by analyzing the quarterly data of China's 2008 2017 GDP and stock market turnover. The data are mainly from the People's Republic of China National Bureau of statistics and the China Securities Regulatory Commission (China Securities Regulatory Commission) website.

From "Fig. 1", it can be seen that the quarterly data of GDP and stock turnover showed a significant seasonal trend before the adjustment, and the trend of GDP showed an annual increase trend. However, in 2015, the turnover of China's stock market reached its peak in 2015, showing a concussion trend before 2015, and began to fall after 2015, which was mainly related to macroeconomic regulation and the "stock" in 2015. It is necessary and important to study the internal relations between the turnover of China's stock market and the macroeconomic growth.

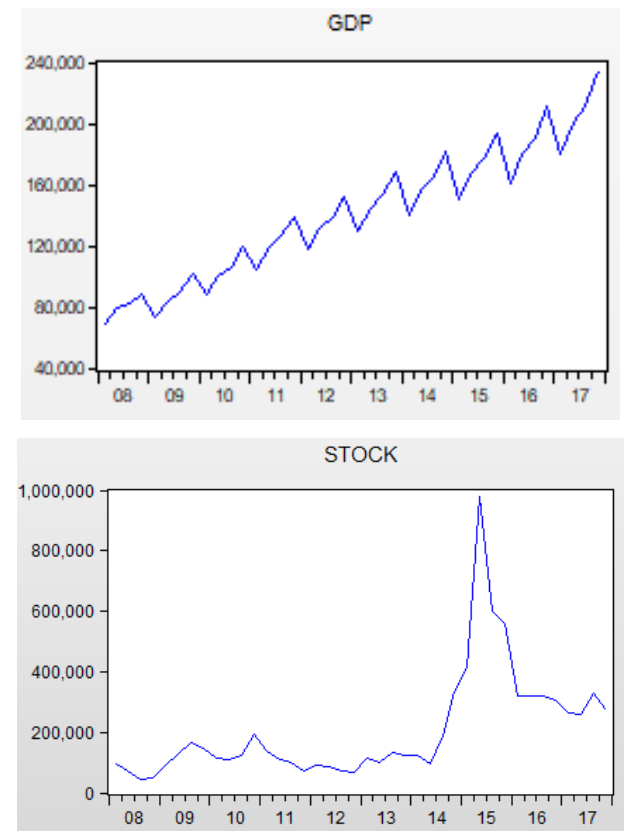

Fig. 1. GDP and STOCK turnover in each quarter of 2008-2017 years before the season adjustment.

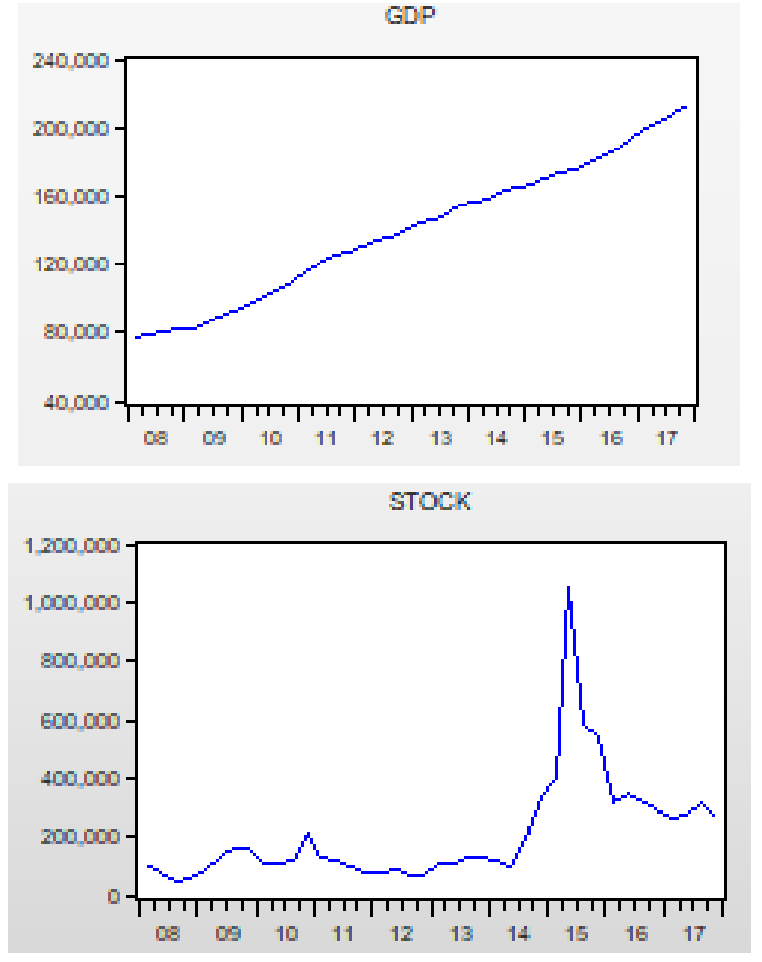

Fig. 2. GDP and STOCK turnover for seasonally adjusted 2008-2017 years.

\section{EMPIRICAL ANALYSIS}

By using the X-11 seasonal multiplication, the GDP and stock market turnover data of the seasonal trend of "Fig. 2" are eliminated. On this basis, the unit root test of the GDP growth rate and the stock market growth rate sequence is carried out to determine the stability of the two sets of sequences. Secondly, the maximum lagging order based on the VAR model is obtained with the aid of the Johansen Association. The whole test exams whether there is a cointegration relationship between the GDP growth rate $\Delta$ lngdpsa and the stock market growth rate $\Delta \operatorname{lnft}$, and further studies on this basis.

\section{A. Unit Root Test}

TABLE I. ADF UNIT-SAMPLE TEST RESUlTS

\begin{tabular}{|l|l|l|l|l|}
\hline variables & $\begin{array}{c}\text { Augmented } \\
\text { Dickey-Fuller } \\
\text { test ststistic }\end{array}$ & $\begin{array}{c}\text { 5\% critical } \\
\text { value }\end{array}$ & $\begin{array}{c}\mathbf{1 0 \%} \text { critical } \\
\text { value }\end{array}$ & $\begin{array}{l}\text { stable } \\
\text { or not }\end{array}$ \\
\hline $\mathrm{gs}$ & -2.337657 & -3.533083 & -3.202445 & not \\
\hline $\mathrm{m}$ & -2.467782 & -2.938987 & -2.607932 & not \\
\hline$\Delta \mathrm{gs}$ & -3.499563 & -3.529758 & -3.196411 & yes \\
\hline$\Delta \mathrm{m}$ & -5.480008 & -3.529758 & -3.196411 & yes \\
\hline
\end{tabular}

In order to test whether there is a cointegration relationship between the GDP growth rate and the stock market growth rate sequence, the ADF test GDP is used to test the stability of the stock market turnover. From the test results of "Table I", we can see that both the GDP and the stock market turnover are nonstationary. The unit root test of the GDP growth rate and the stock market growth rate 
sequence shows that the GDP growth rate and the stock market growth rate are stable, which indicates that the GDP growth rate and the stock market growth rate sequence are stable. This shows that GDP and the sequence of transactions with the stock market is the first order stationary, that is, the I (1) process.

\section{B. Johansen Cointegration Test}

TABLE II. JOHANSEN COINTEGRATION TEST RESUlTS

\begin{tabular}{|l|l|c|l|l|}
\hline $\begin{array}{c}\text { Hypothesized No.of } \\
\text { CE(s) }\end{array}$ & Eigenvalue & $\begin{array}{c}\text { Trace } \\
\text { Statistic }\end{array}$ & $\begin{array}{c}\text { 5\% Critical } \\
\text { Value }\end{array}$ & Prob. \\
\hline None & 0.356053 & 28.18564 & 15.49471 & 0.0004 \\
\hline At most 1 & 0.260358 & 11.46036 & 3.841466 & 0.0007 \\
\hline
\end{tabular}

According to the value of trace statistics in "Table II", there is a cointegration relationship between a value greater than 5\% confidence level and a cointegration relationship between the GDP growth rate and the stock market growth rate, which reflects the long-term equilibrium relationship between the GDP growth rate and the stock market growth rate. The sustained growth of macro-economy provides impetus and foundation for the development of stock market. First, the increase in commodity demand has directly promoted the growth of stock trading scale. Driven by the huge demand for commodities in the national economy, a large number of enterprises have actively entered the management risk of stock market, and directly promoted the continuous activity of stock varieties.

\section{Granger Causal Test}

TABLE III. GRANGER CAUSALITY TEST RESUlts

\begin{tabular}{|l|l|l|}
\hline \multicolumn{1}{|c|}{ Null Hypothesis } & \multicolumn{1}{c|}{ F-Statistic } & \multicolumn{1}{c|}{ Prob. } \\
\hline GDP does not Granger Cause STOCK & 7.17863 & 0.0111 \\
\hline STOCK does not Granger Cause GDP & 0.91244 & 0.3458 \\
\hline
\end{tabular}

The result of test shows that GDP is the Granger reason of stock market turnover, and the turnover of stock market is not the Granger reason of GDP. This means that GDP leads to stock market turnover, while stock market turnover does not guide GDP. This also with the rapid development of China's national economy, China's stock market scale has steadily expanded in recent years, especially in recent years the stock market activity significantly increased, and the national economic relevance of rapid increase.

\section{Variance Decomposition}

"Fig. 3" shows the variance between the GDP and the stock market turnover, the variance of the long-term effect on the turnover of the stocks, when the lag period is 1 , the total variance $100 \%$ comes from the body, and, as the lag period increases, The total variance from the stock market turnover of its own part of the downward trend, eventually to $86 \%$, and from the GDP part of the rise, and eventually to $15 \%$. The variance of the long-term effects of GDP changes, when the lag period is 1 , the total variance mostly comes from the GDP, as the lag period increases, the total variance comes from its own part is declining trend, then it tends to be
$89 \%$, while the portion from the stock market turnover is rising, and eventually tends to $11 \%$. It can be seen that in the interaction between GDP and stock market turnover, the influence of GDP is bigger, stronger and more obvious.

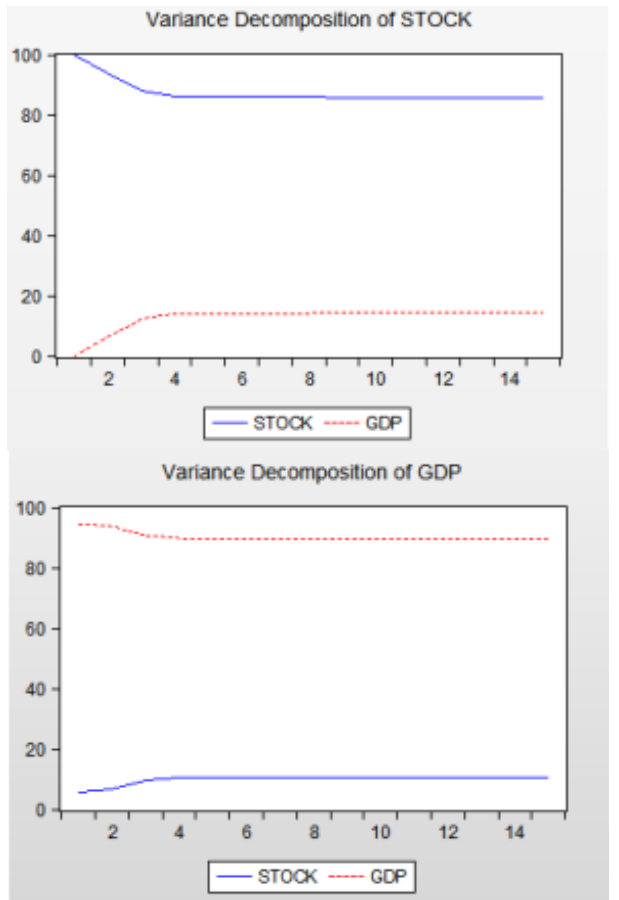

Fig. 3. GDP and the variance decomposition of stock market turnover.

\section{E. Impulse Response Function}

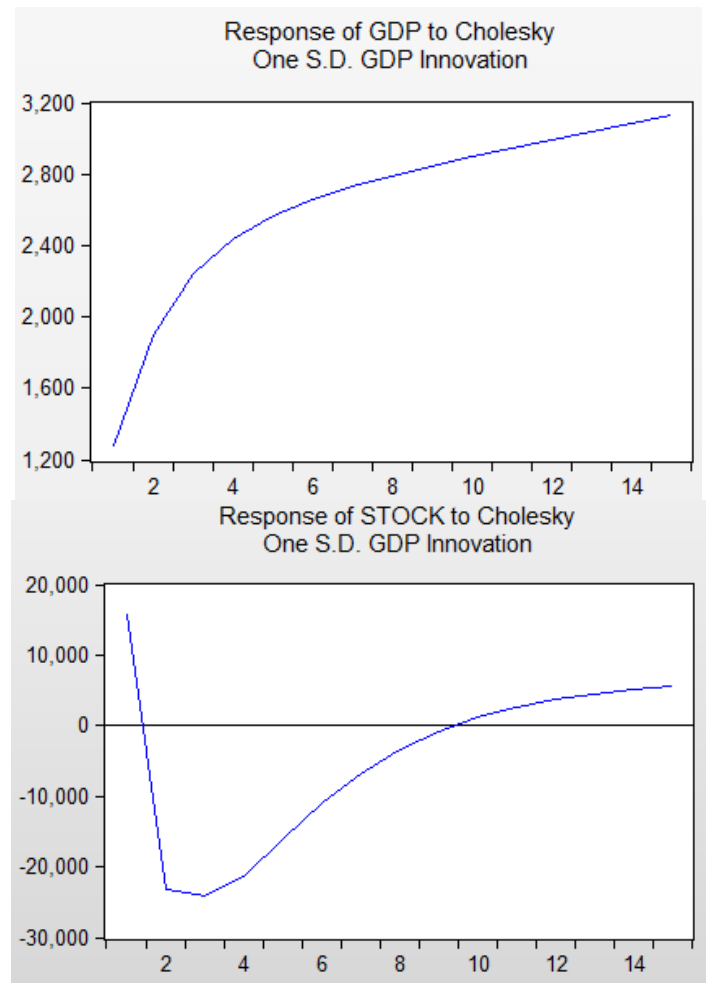

Fig. 4. Impulse response of GDP to GDP and stock turnover. 


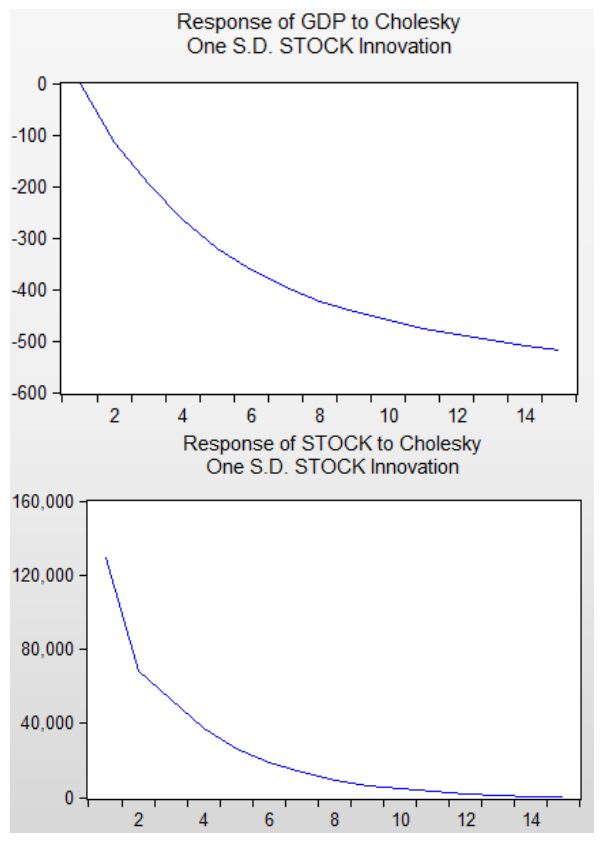

Fig. 5. Impulse response of stock turnover to GDP and stock turnover.

From "Fig. 4" and "Fig. 5", the abscissa indicates the tracking period, and the selection time is 15 quarters, and the ordinate indicates the pulse response level. GDP has a great impact on its own volatility in the current quarter, and tends to rise slowly; stocks react strongly to GDP shocks. The first phase is near zero, reaching the minimum in the second to third phases, and then gradually recovering . After the ninth period, it started to be positive, with an upward trend greater than zero. For the impact from the stock market, the stock market has a negative correlation with its own shock response, and the degree of negative correlation is greater with time. The impact of GDP on the stock market is positively correlated and strong, and its impact slows and gradually approaches zero over time.

In summary, we can find that the impulse response efficiency of GDP growth to the development of the stock market is better than the development of the stock market to promote GDP growth, so GDP growth has a great impact on the development of the stock market.

\section{CONCLUSION}

There is a long-term equilibrium and stable relationship between China's economic growth and stock market, and economic growth promotes the development of stock market. The sustained growth of the macro-economy provides the impetus and foundation for the development of the stock market. Economic growth has increased the demand for commodities, increased the sales of commodities, increased the profits of the enterprises, expanded the investment, increased the financing capacity, and increased the volume and volume of the stock market. Therefore, with the growth of the national economy, the stock market is developing rapidly.

Economic growth determines financial development. GDP is the Granger cause of the stock market turnover. GDP leads the stock market, and the variance from GDP is greater than the variance from the stock market turnover. The growth of GDP has a guiding role for the development and promotion of the stock market, and the stock market increases with the growth of the economy.

\section{REFERENCES}

[1] S.J.Cochran and I. Mansur, "Expected return and econo mic fac-tors: a GARCH appr oach," APPlied Financial Economics,pp.243254,1993.

[2] Pagno M, "Financial Markets and Growth: an overview". Euro-pean Eocnomic Review,pp. 613-632,1993.

[3] Yi Danhui, "Data Analysis and Application of Eviews". Bijing: China Statistics Press, pp.166-179,2002.

[4] Gao Tiemei, "Econometric analysis and modeling". Beijing: Tsinghua University Press, pp.249-301,2006. 